九州大学学術情報リポジトリ

Kyushu University Institutional Repository

\title{
Emotion colors time perception unconsciously
}

\section{Yamada, Yuki}

Faculty of Human-Environment Studies, Kyushu University | NTT Communication Science Laboratories

Kawabe, Takahiro

Faculty of Human-Environment Studies, Kyushu University | NTT Communication Science Laboratories

http://hdl. hand le. net/2324/19910

出版情報：Consciousness and Cognition. 20 (4)，pp. 1835-1841，2011-07-20. Elsevier バージョン：

権利関係 : 


\title{
Emotion colors time perception unconsciously
}

\author{
Yuki Yamada, Takahiro Kawabe
}

\begin{abstract}
Emotion modulates our time perception. So far, the relationship between emotion and time perception has been examined with visible emotional stimuli. The present study investigated whether invisible emotional stimuli affected time perception. Using continuous flash suppression, which is a kind of dynamic interocular masking, supra-threshold emotional pictures were masked or unmasked depending on whether the retinal position of continuous flashes on one eye was consistent with that of the pictures on the other eye. Observers were asked to reproduce the perceived duration of a frame stimulus that was concurrently presented with a masked or unmasked emotional picture. As a result, negative emotional stimuli elongated the perceived duration of the frame stimulus in comparison with positive and neutral emotional stimuli, regardless of the visibility of emotional pictures. These results suggest that negative emotion unconsciously accelerates an internal clock, altering time perception.
\end{abstract}

\section{Introduction}

This is a preprint version of the article published at Consciousness and Cognition 2011; 20:

1835-1841

Original link:

http://dx.doi.org/10.1016 /j.concog.2011.06.016

Correspondence to:

Yuki Yamada, Faculty

of Human-Environment

Studies, Kyushu

University,

6-19-1 Hakozaki

Higashi-ku, Fukuoka

812-8581, Japan

yamadayuk@gmail.com
A major interest of investigators of emotion is how emotion affects various kinds of mental information processing (Dolan, 2002; Phelps, 2006). Previous studies have suggested that exogenously evoked (especially fear-related) emotion enhances visual processing of emotional stimuli themselves in terms of detection (e.g., Anderson \& Phelps, 2001; Dijksterhuis \& Aarts, 2003; Hansen \& Hansen, 1988; Öhman, Flykt, \& Esteves, 2001) and memory (e.g., Adolphs, Cahill, Schul, \& Babinsky, 1997; Bradley, Greenwald, Petry, \& Lang, 1992; Brown \& Kulik, 1977; De Houwer \& Hermans, 1994; Harris \& Pashler, 2005; Loftus, 1979; Rubin \& Friendly, 1986). In addition, viewing emotional stimuli influences visual processing of subsequently presented stimuli. For example, the prior presentation of emotional stimuli yields a faster or slower reaction time to a subsequent target depending on the emotional congruency between the prime and target stimuli (the affective priming effect: Fazio, Sanbonmatsu, Powell, \& Kardes, 1986; Hermans, De Houwer, \& Eelen, 2001; Murphy \& Zajonc, 1993) and the impairment of subsequent target identification (Anderson, 2005; Most, Chun, Widders, \& Zald, 2005; Most, Smith, Cooter, Levy, \& Zald, 2007; Smith, Most, Newsome, \& Zald, 2006). The prior presentation of emotional stimuli also affects low-level visual processing of subsequent stimuli (Bocanegra \& Zeelenberg, 2009b; Phelps, Ling, $\&$ Carrasco, 2006). These findings suggest that emotional stimuli attract visual attention and modulate sensory processing at their location as long as processing of the emotional stimuli holds the attention (Bocanegra \& Zeelenberg, 2009a; Mathewson, Arnell, \& Mansfield, 2008).

A number of studies have demonstrated that emotional information is processed unconsciously (for a review see Tsuchiya \& Adolphs, 2007). It is known that the affective priming effect occurs even when the prime emotional stimuli are subliminally presented (Ghuman \& Bar, 2006; Murphy \& Zajonc, 1993; Rotteveel, de Groot, Geutskens, \& Phaf, 2001; Sweeny, Grabowecky, Suzuki, \& Paller, 2009). Likewise, a previous study (Jiang, Costello, Fang, Huang, \& He, 2006) found that erotic images captured spatial attention at their position even though these images were rendered subjectively invisible by using continuous flash suppression. Continuous flash suppression is a strong interocular masking in which dynamic random patterns continuously presented to one eye suppress the visibility of an image presented to the other eye (Tsuchiya \& Koch, 2005). In addition, face stimuli with a fearful expression resulted in conscious perception faster than those with happy and neutral expressions, while they were rendered invisible by continuous flash suppression (Yang, Zald, \& Blake, 2007). Continuous flash suppression can render visual stimuli invisible for a long period (for several tens of seconds). By exploiting continuous flash suppression, a previous study demonstrated that invisible information was integrated with visible information (e.g., Kawabe \& Yamada, 2009). Thus, it is possible to investigate how ongoing processing for visible information is affected by invisible emotional stimuli.

Emotion also affects our time perception (Droit-Volet \& Gil, 2009; Droit-Volet \& Meck, 2007; Wittmann, 2009). Previous studies have revealed that visible emotional stimuli modulated time perception. To achieve this result these studies used emotional facial expression stimuli (Bar-Haim, Kerem, Lamy, \& Zakay, 2010; Droit-Volet, Brunot, \& Niedenthal, 2004; Effron, Niedenthal, Gil, \& Droit-Volet, 2006; Gil, 
Niedenthal, \& Droit-Volet, 2007), taboo words (Tipple, 2010), emotional pictures (Angrilli, Cherubini, Pavese, \& Manfredini, 1997; Gil, Rousset, \& Droit-Volet, 2009; Grommet et al., 2011), emotional sounds (Noulhiane, Mella, Samson, Ragot, \& Pouthas, 2007), and music (Droit-Volet, Bigand, Ramos, \& Bueno, 2010). However, the emotional effects on time perception with invisible emotional stimuli are still unclear. As described earlier, employing continuous flash suppression realizes a long presentation of invisible emotional stimuli. Therefore, we used continuous flash suppression to clarify the effect of invisible emotional stimuli on time perception.

The present study tested whether invisible emotional stimuli affected time perception. Specifically, emotional (positive or negative) or neutral pictures were rendered invisible when these pictures and continuous flashes were presented at corresponding retinal locations of different eyes. In addition, a square frame was presented outside the pictures. The frame was not subject to continuous flash suppression because the retinal locations of the frame on one eye did not correspond to those of continuous flashes on the other eye. The subjective duration of a square frame outside the pictures in the presence of continuous flashes was measured. In this case, the square frame and continuous flashes were visible but the pictures were invisible. A previous study showed a spill-over effect of an emotional stimulus to a simultaneously presented remote stimulus (Sweeny, Grabowecky, Paller, \& Suzuki, 2009). Based on this finding, the time perception of the frame stimulus would be influenced by simultaneously presented, invisible emotional pictures at a remote position.

\section{Method}

\subsection{Observers}

Twenty-six observers participated in the experiment, and they were randomly assigned to masked $(N=11)$ and unmasked $(N=14)$ conditions (See subsequent subsections for details of the conditions). One observer did not complete the experiment because she/he could not binocularly fuse fixation marks presented to each eye. The observers reported normal or corrected-to-normal visual acuity. They were naive as to the purpose of the experiment.

\subsection{Apparatus}

Stimuli were presented on a 19-in. CRT monitor (RDF193H, Mitsubishi, Japan). The resolution of the monitor was 1024 x 768 pixels, and the refresh rate was $100 \mathrm{~Hz}$. The presentation of stimuli and collection of data were computer-controlled (Mac Pro; Apple). Using a photometer (3298F; Yokogawa, Japan), we linearized the luminance emitted from the monitor with gamma correction. The observers viewed the stimuli through a mirror stereoscope (Screenscope; Stereoaids, Australia).

\subsection{Stimuli}

The stimuli were generated by MATLAB (Mathworks Inc.) with the Psychtoolbox extension (Brainard, 1997; Pelli, 1997). Fig. 1 shows the stimuli used in the experiment. The stimuli consisted of two fixation marks, two square outlines, continuous flashes, a frame stimulus, and pictures displayed on a gray background $\left(43.5 \mathrm{~cd} / \mathrm{m}^{2}\right)$. Each fixation mark was composed of two concentric rings with a radius of $0.24^{\circ}$ and $0.48^{\circ}$ in visual angle, respectively. The luminance of each ring was $91.0 \mathrm{~cd} / \mathrm{m}^{2}$. To ensure a binocular fusion, we presented a square outline to each eye. The square outlines had a side of $14.4^{\circ}$, and a border width of $0.19^{\circ}$. The luminance of the border was $91.0 \mathrm{~cd} / \mathrm{m}^{2}$. Four lines (length: $0.96^{\circ}$ ) were attached perpendicularly to each square outline at midpoints of each side. Its luminance and border width was the same as the square outlines. There were two conditions of mask in terms of the correspondence of the retinal location between continuous flashes on one eye and stimulus images on the other eye. In the masked condition, continuous flashes consisted of a clutter of approximately two hundred colorful rectangles. The center of each rectangle was randomly
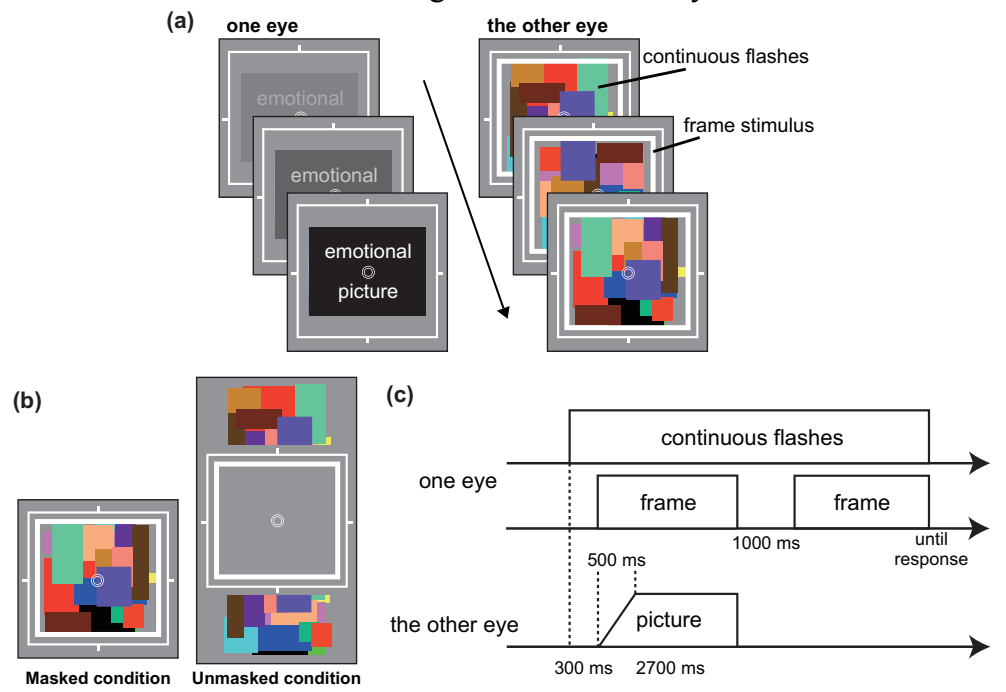

Fig. 1. (a) Schematic representation of the stimuli used in the experiment (not scaled). One eye viewed a frame stimulus and continuous flashes, while the other eye viewed a picture which contrast was linearly ramped up to the maximum during the first $500 \mathrm{~ms}$. (b) Examples of masks in the masked and unmasked conditions. (c) Time course of the stimulus presentation. 
positioned within an imaginary square with sides of $9.6^{\circ}$. On the other hand, in the unmasked condition, continuous flashes consisted of two clutters of approximately 100 colorful rectangles. The center of each rectangle was randomly positioned within an imagery rectangle with sides of $4.8^{\circ} \times 9.6^{\circ}$. The side lengths of the rectangles were randomly varied from $0.05^{\circ}$ to $1.4^{\circ}$. The color, position and side length of each rectangle were randomly altered at $12.5 \mathrm{~Hz}$. In the masked condition, the center of continuous flashes corresponded to one of the fixation marks. In the unmasked condition, each center of continuous flashes was $6.2^{\circ}$ above and below the center of the fixation marks, respectively so that the retinal location of continuous flashes on one eye never covered that of stimulus images on the other eye. The fixation and the square outline were dichoptically presented to both eyes without binocular disparity. One of the pictures was presented to one eye while continuous flashes were presented to the other eye. The frame stimulus was presented to the same eye receiving the continuous flashes. The frame stimulus had a side of $12.5^{\circ}$, and a border width of $0.38^{\circ}$. The luminance of the frame stimulus was $91.0 \mathrm{~cd} / \mathrm{m}^{2}$.

Thirty pictures were chosen from the International Affective Picture System (IAPS; Lang, Bradley, \& Cuthbert, 2005) (Appendix A). The size of each picture was $9.0^{\circ} \times 12.0^{\circ}$. The picture was centered at either of the fixation marks. Ten pictures each were used as positive (mean valence rating 7.93 ; mean arousal rating $6.15)$, negative $(2.74 ; 6.14)$, and neutral stimuli $(4.94 ; 6.13)$. For valence rating scores of each picture, a one-way between-groups analysis of variance (ANOVA) with emotional valence (positive, negative, and neutral) as a factor showed a significant main effect $[F(2,27)=$ 875.14, $p<.0001]$. Multiple comparisons using Ryan's method (Ryan, 1960) revealed that the

\footnotetext{
${ }^{1}$ In a supplementary experiment, we measured discriminability of pictures in the masked and unmasked conditions. Seven naive adults were participated as observers. The apparatus, stimuli, and procedure were same as those used in the main experiment except for the following: The second frame stimulus was not presented. Observers were instructed to discriminate the emotional valence of each picture by a three-alternative forced choice (negative, positive, or neutral) after the offset of the first frame stimulus and the pictures. Rapid responding was not required. An experimental block contained 30 pictures same as the pictures used in the main experiment and was repeated five times: Consequently there were 150 trials in total. For each stimulus valence, discriminability (measured with d0) was calculated (Green \& Swets, 1966) from the trials wherein each observer reported the picture was invisible in the masked condition and visible in the unmasked condition. Specifically, $18.0 \%$ and $1.8 \%$ of the data in the masked and unmasked conditions, respectively, were excluded from the analysis. As a result, one-sample $t$-test revealed that $d^{\prime}$ in the masked condition (mean $d^{\prime}=0.01$ ) did not significantly differ from $0[t(6)=0.08, p>.94]$, while $d$ ' in the unmasked condition (mean $d^{\prime}=1.33$ ) was significantly higher than $1[t(6)=3.39, p<.02]$. These results suggested that observers could not discriminate the pictures in the masked condition at all and could successfully discriminate the pictures in the unmasked condition.
}

rating score of positive stimuli was higher than that of neutral $[t(27)=24.02, p<.0001]$ and negative stimuli $[t(27)=41.68, p<.0001]$. Moreover, the rating score of neutral stimuli was higher than that of negative stimuli $[t(27)=17.66$, $p<.0001]$. For arousal rating scores of each pictures, a one-way between-groups ANOVA with emotional valence as a factor did not show a significant main effect $[F(2,27)=0.01, p>.99]$. Thus, we confirmed that the three types of emotional stimuli significantly differed in valence but not in arousal.

\subsection{Procedure}

Observers were individually tested in a dark room and they viewed stimuli through a mirror stereoscope. The viewing distance was $40 \mathrm{~cm}$. The square outlines and fixation marks were presented throughout the experiment. Observers pressed the space bar to start each trial. After 300 $\mathrm{ms}$, the presentation of continuous flashes was started. Five hundred milliseconds after pressing the space bar, a picture was presented at the center of a square outline of one eye. The contrast of the picture increased linearly at a rate of $2.5 \%$ every $10 \mathrm{~ms}$ up to full contrast. This was done so that visual transients due to the abrupt onset of the picture would not help access to consciousness (Yang et al., 2007). At the same time as the picture appeared, the frame stimulus was presented with full contrast from the start. The picture and the frame stimulus were presented for $2700 \mathrm{~ms}$, and they disappeared abruptly. Then, $1000 \mathrm{~ms}$ afterwards, only the frame stimulus reappeared and this lasted until the observers made their response. The observers were asked to reproduce the perceived duration of the first frame stimulus by pressing the space bar when they thought that the second frame stimulus had been presented for the same duration as the first one. Additionally, in the masked condition, when the picture was consciously seen, the observers were asked to press an assigned key instead of the space bar. On the other hand, in the unmasked condition, the observers were asked to press the key when the picture was not consciously seen. Each observer performed 30 trials: three emotion conditions (positive, negative, and neutral) x 10 stimuli. The trial order was randomized across observers.

\section{Results}

We focused on the following two indices: (1) A $T$-corrected score provided by the formula $\left[T_{\text {corrected }}=\left(T_{\text {reproduced }}-T_{\text {actual }}\right) / T_{\text {actual }}\right]$ (Angrilli et al., 1997; Brown, 1985; Noulhiane et al., 2007) 
and (2) the coefficient of variation (CV) computed by dividing the standard deviation by the mean (Brown, 1997; Noulhiane et al., 2007) for each observer. Due to machine downtime, the presentation duration in some trials became longer than $2700 \mathrm{~ms}$ (in $9.1 \%$ of the trials), and we did not submit these data to further analysis. Moreover, we analyzed the data from trials in which the picture was invisible in the masked condition and visible in the unmasked condition. Specifically, $19.1 \%$ and $0 \%$ of the data in the masked and unmasked conditions, respectively, were also excluded from further analysis.

A two-way mixed between-within subjects analysis of variance (ANOVA) on the $T$-corrected scores with mask (masked vs. unmasked) as a between-subjects factor and emotion (positive, negative, and neutral) as a within-subject factor was performed (Fig. 2). The ANOVA showed a significant main effect of emotion $[F(2,44)=8.39, p<.0009]$ and a marginally significant main effect of mask $[F(1$, $22)=3.26, p<.09]$. However, there was no significant interaction $[F(2,44)=0.75, p>.48]$. Multiple comparisons using Ryan's method revealed that the frame duration in the negative condition was significantly overestimated compared to that in the positive $[t(44)=3.60, p$ $<.0009]$ and neutral $[t(44)=3.60, p<.0009]$ conditions.

Moreover, to test the difference from zero (actual duration), we conducted individual one-sample $t$-tests (two-tailed) which revealed that the mean $T$-corrected score in each condition was significantly smaller than zero $(p s<.03)$, except for that in the masked-negative condition $(p>.23)$.

A two-way mixed between-within subjects ANOVA on CV with mask as a between-subjects factor and emotion as a within-subject factor showed no significant main effects [mask: $F(1$, $22)=2.03, p>.16$; emotion: $F(2,44)=0.26, p$ $>.77]$ and interaction $[F(2,44)=2.44, p>.09]$.

\section{Discussion}

The objective of the present study was to examine whether invisible emotional stimuli affected concurrent time perception. We controlled the visibility ${ }^{1}$ of emotional stimuli by using continuous flash suppression (Tsuchiya \& Koch, 2005). As a result, time perception with negative emotional stimuli was significantly longer than with positive and neutral emotional stimuli, while there was no interaction between mask and emotion. These results suggest that time perception is affected by emotion regardless of the visibility of emotional stimuli. On the

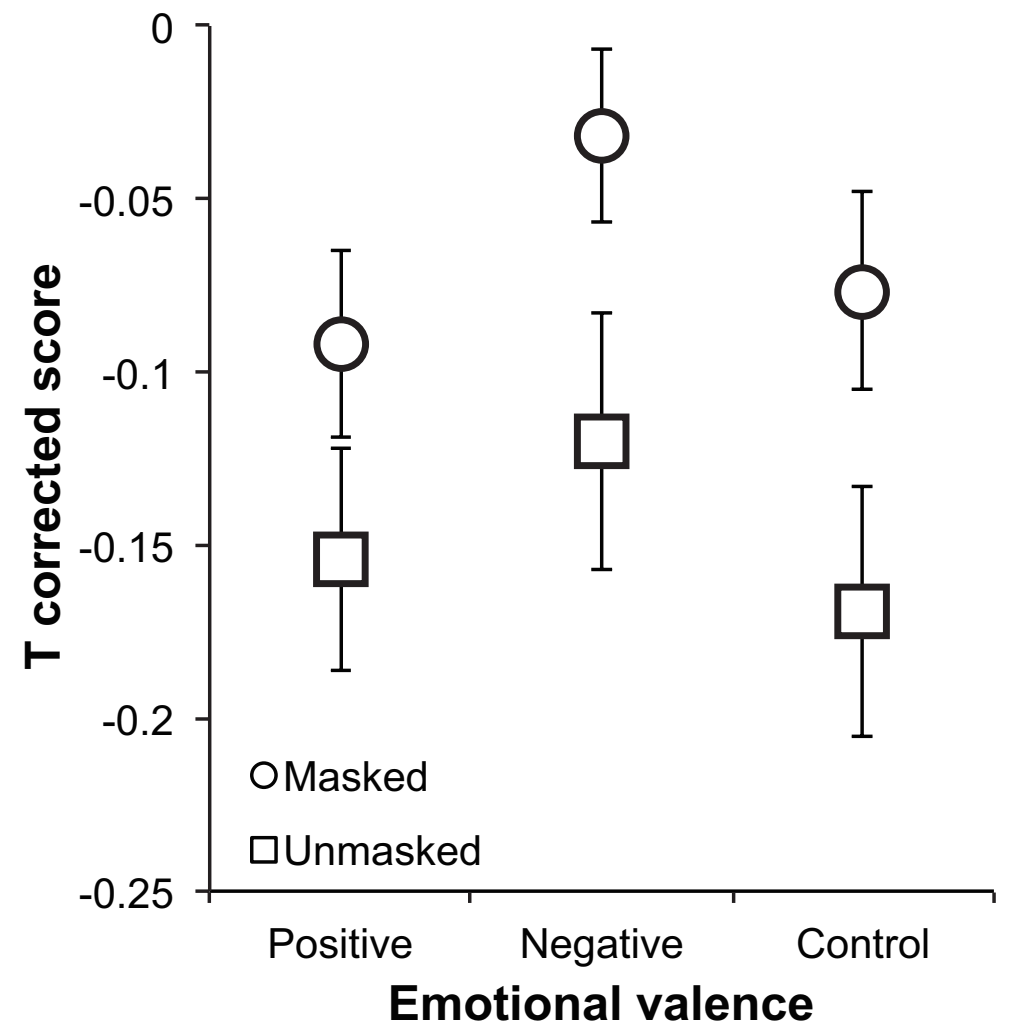

Fig. 2. The $T$-corrected score $\left[T_{\text {corrected }}=\left(T_{\text {reproduced }}-T_{\text {actual }}\right) / T_{\text {actual }}\right]$ in each condition. Error bars denote standard errors of the mean

other hand, the variability of temporal estimation was affected by neither the presence/absence of mask nor emotional valences. The pattern of these results was consistent with previous studies pertaining to the effect of visible emotional stimuli on time perception (e.g., Angrilli et al., 1997; Grommet et al., 2011; Noulhiane et al., 2007), suggesting that unconscious emotional processing as well as conscious emotional processing alters time perception.

The elongation of time perception with the masked presentation of negative stimuli compared to positive or neutral stimuli suggests that unconscious preferential processing of negative emotion affected conscious time perception. A number of studies have documented that negative stimuli could be processed even when the stimuli were subjectively invisible (e.g., Dijksterhuis \& Aarts, 2003; Öhman \& Soares, 1994,). Moreover, previous studies on subliminal affective priming have reported that invisible negative stimuli influenced subsequent emotional processing (e.g., Murphy \& Zajonc, 1993), sometimes more than invisible positive stimuli do (Murphy, Monahan, \& Zajonc, 1995; Sato \& Aoki, 2006). Consistent with these studies, the present study provided novel evidence indicating that unconscious emotional processing is linked to ongoing 
temporal processing.

The general tendency of temporal underestimation found in the present study may be related to attentional modulation of the internal clock. Researchers on time perception have frequently referred to a hypothetical internal clock that produces subjective duration by counting physical stimulus duration with variable pacemaker pulses and accumulating the pulses (e.g., Droit-Volet \& Wearden, 2002; Gibbon, 1977; Treisman, 1963). The accumulator sums the pulses, and the number of pulses in a given period represents subjective duration. If attention is diverted to non-temporal information, the number of pulses sent to the accumulator is reduced, resulting in time underestimation. Hence, in our experiment, it is likely that attention oriented to salient signals of dynamic changes in the continuous flashes caused the general underestimation. Furthermore, attention to spatial properties (i.e. salient color distribution) or semantic information of pictures might have led to the somewhat greater underestimation in perceived durations in the unmasked condition compared to that in the masked condition, though the main effect of mask was marginal. ${ }^{2}$

The difference in the effects between the negative emotion pictures and positive emotion pictures possibly reflects the influence of emotional factors on temporal processing. The results showed that the temporal estimates in the negative condition were longer than in the positive and neutral conditions. The time elongation by negative emotion has been reported in previous studies. Angrilli et al. (1997) found that durations of negative pictures were overestimated than positive pictures at a high level of arousal, while durations of negative pictures were underestimated than positive pictures at a low level of arousal. The researchers explained that attentional and emotional mechanisms were differently involved in time perception depending on low and high arousal, respectively. That is, at the low arousal level, attentional engagement to negative pictures induced a reduction of pulses that were sent to accumulator, leading to the temporal underestimation of the negative pictures, as we mentioned earlier. On the other hand, at the high

\footnotetext{
${ }^{2}$ To further test the effect of visibility of a picture, we performed the comparison between $T$-corrected scores in 'invisible trials' and 'visible trials' in the masked condition. Data from two observers were excluded because there was no visible or invisible trial. A two-tailed, paired $t$-test revealed that the presentation duration of the target frame in the invisible trials (mean $T$-corrected score $=-0.06$ ) was significantly overestimated compared to that in the visible trials (mean $T$-corrected score $=-0.50$ ) $[t(8)=4.49, p<.003]$.
}

arousal level, emotional mechanism was important for time perception. An increase of arousal increases the clock speed of the pacemaker (Angrilli et al., 1997; Droit-Volet \& Meck, 2007), and this acceleration caused the temporal overestimation. In particular, negative emotion is linked to avoidance reactions (Duckworth, Bargh, Garcia, \& Chaiken, 2002). Because the aversive reactions are ecologically urgent adaptive behaviors for survival (e.g., attack or withdrawal), especially at the high arousal level, negative emotion may accelerate the internal clock, resulting in the time elongation in the negative condition compared to the positive and neutral conditions. The present study used pictures with relatively high arousal, therefore Angrilli et al.'s explanation is applicable to our finding. Importantly, our results suggest that the acceleration of the pacemaker by negative emotion occur regardless of the visibility of stimuli.

In sum, the present study demonstrated that emotion affects time perception unconsciously. The presentation of invisible as well as visible negative pictures elongated the perceived duration of a visible target stimulus. The results suggest that conscious and unconscious emotional processing have an impact on the internal clock mechanism. Moreover, the present study provided a new technique to test the effect of invisible stimulus information on time perception. For example, effects of properties of invisible stimuli (size, luminance, number, and motion), spatial attention driven by invisible visual transients, and invisible facial expressions can be tested by means of this technique. A limitation of our study is lack of stimulus variation. Previous studies used high- and low-arousal pictures with several duration lengths in order to provide a better description of the temporal judgments (mean accuracy) and explore the mechanisms underlying the emotional effects (attention vs. arousal) (Angrilli et al., 1997; Noulhiane et al., 2007). However, we used only high-arousal pictures with the presentation duration of $2700 \mathrm{~ms}$, and hence there were not ample data for testing the interactive effects among emotional valences, arousal levels, and presentation duration. These important parameters have to be elaborated by further investigation.

\section{Acknowledgments}

This work was supported by a Grant-in-Aid for JSPS Fellows from the Japan Society for the Promotion of Science (Y.Y.) and the Kyushu University Research Superstar Program (T.K.). 


\section{Appendix A}

See Table A1.

\section{References}

Adolphs, R., Cahill, L., Schul, R., \& Babinsky, R. (1997). Impaired declarative memory for emotional stimuli following bilateral amygdala damage in humans. Learning and Memory, 4, 291-300.

Anderson, A. K. (2005). Affective influences on the attentional dynamics supporting awareness. Journal of Experimental Psychology: General, 134, 258-281.

Anderson, A. K., \& Phelps, E. A. (2001). Lesions of the human amygdale impair enhanced perception of emotionally salient events. Nature, 411, 305-309.

Angrilli, A., Cherubini, P., Pavese, A., \& Manfredini, S. (1997). The influence of affective factors on time perception. Perception and Psychophysics, 59, 972-982.

Bar-Haim, Y., Kerem, A., Lamy, D., \& Zakay, D. (2010). When time slows down: The influence of threat on time perception in anxiety. Cognition and Emotion, 24, 255-263.

Bocanegra, B. R., \& Zeelenberg, R. (2009a). Dissociating emotion-induced blindness and hypervision. Emotion, 9, 865-873.

Bocanegra, B. R., \& Zeelenberg, R. (2009b). Emotion improves and impairs early vision. Psychological Science, 20, 707-713.

Bradley, M. M., Greenwald, M. K., Petry, M. C., \& Lang, P. J. (1992). Remembering pictures: Pleasure and arousal in memory. Journal of Experimental Psychology: Learning, Memory, and Cognition, 18, 379-390.

Brainard, D. H. (1997). The psychophysics toolbox. Spatial Vision, 10, 433-436.

Brown, S. W. (1985). Time perception and attention: The effects of prospective versus retrospective paradigms and task demands on perceived duration. Perception and Psychophysics, 38, 115-124.

Brown, S. W. (1997). Attentional resources in timing: Interference effects in concurrent temporal and nontemporal working memory tasks. Perception and Psychophysics, 59, 1118-1140.

Brown, R., \& Kulik, J. (1977). Flashbulb memories. Cognition, 5, 73-99.

De Houwer, J., \& Hermans, D. (1994). Differences in the affective processing of words and pictures. Cognition and Emotion, 8 , $1-20$.

Dijksterhuis, A., \& Aarts, H. (2003). On wildebeests and humans: The preferential detection of negative stimuli. Psychological Science, 14, 14-18.

Dolan, R. J. (2002). Emotion, cognition, and behavior. Science, 298, 1191-1194.

Droit-Volet, S., Bigand, E., Ramos, D., \& Bueno, J. L. (2010). Time flies with music whatever its emotional valence. Acta Psychologica, 135, 226-232.

Droit-Volet, S., Brunot, S., \& Niedenthal, P. (2004). Perception of the duration of emotional events. Cognition and Emotion, 18, 849-858.

Droit-Volet, S., \& Gil, S. (2009). The time-emotion paradox. Journal of Philosophical Transactions of the Royal Society Series B - Biological Sciences, 364, 1943-1953.

Droit-Volet, S., \& Meck, W. H. (2007). How emotions colour our time perception of time. Trends of Cognitive Sciences, 11, 504-513.

Droit-Volet, S., \& Wearden, J. (2002). Speeding up an internal clock in children? Effects of visual flicker on subjective duration. Quarterly Journal of Experimental Psychology, 55B, 193-211.

Duckworth, K. L., Bargh, J. A., Garcia, M., \& Chaiken, S. (2002). The automatic evaluation of novel stimuli. Psychological Science, 13, 513-519.

Effron, D., Niedenthal, P. M., Gil, S., \& Droit-Volet, S. (2006). Embodied temporal perception of emotion. Emotion, 6, 1-9.

Fazio, R. H., Sanbonmatsu, D. M., Powell, M. C., \& Kardes, F. R. (1986). On the automatic activation of attitudes. Journal of Personality and Social Psychology, 2, 229-238.

Ghuman, A. S., \& Bar, M. (2006). The influence of non remembered affective associations on preference. Emotion, 6, 215-223.

Gibbon, J. (1977). Scalar expectancy theory and Weber's law in animal timing. Psychological Review, 84, 279-325.

Gil, S., Niedenthal, P. M., \& Droit-Volet, S. (2007). Anger and temporal perception in children. Emotion, 7, 219-225.

Gil, S., Rousset, S., \& Droit-Volet, S. (2009). How liked and disliked foods affect time perception. Emotion, 9, 457-463.

Green, D. M., \& Swets, J. A. (1966). Signal detection theory and psychophysics. New York: Wiley.

Grommet, E. K., Droit-Volet, S., Gil, S., Hemmes, N. S., Baker, A. H., \& Brown, B. (2011). Time estimation of fear cues in human observers. Behavioural Processes, 86, 88-93.

Hansen, C. H., \& Hansen, R. D. (1988). Finding 
the face in the crowd-An anger superiority effect. Journal of Personality and Social Psychology, 54, 917-924.

Harris, C. R., \& Pashler, H. (2005). Enhanced memory for negatively emotionally charged pictures without selective rumination. Emotion, 5, 191-199.

Hermans, D., De Houwer, J., \& Eelen, P. (2001). A time course analysis of the affective priming effect. Cognition and Emotion, 15, 143-165.

Jiang, Y., Costello, P., Fang, F., Huang, M., \& He, S. (2006). A gender- and sexual orientation-dependent spatial attentional effect of invisible images. Proceedings of the National Academy of Sciences of the United States of America, 103, 17048-17052.

Kawabe, T., \& Yamada, Y. (2009). Invisible motion contributes to simultaneous motion contrast. Consciousness and Cognition, 18, $168-175$.

Lang, P. J., Bradley, M. M., \& Cuthbert, B. N. (2005). International affective picture system (IAPS): Affective ratings of pictures and instruction manual. Technical Report A-6. Gainesville, FL: University of Florida.

Loftus, E. F. (1979). Eyewitness testimony. Cambridge, MA: Harvard University Press.

Mathewson, K. J., Arnell, K. M., \& Mansfield, C. A. (2008). Capturing and holding attention: The impact of emotional words in rapid serial visual presentation. Memory and Cognition, 36, 182-200.

Most, S. B., Chun, M. M., Widders, D. M., \& Zald, D. H. (2005). Attentional rubbernecking: Cognitive control and personality in emotion-induced blindness. Psychonomic Bulletin and Review, 12, 654-661.

Most, S. B., Smith, S. D., Cooter, A. B., Levy, B. N., \& Zald, D. H. (2007). The naked truth: Positive arousing distractors impair rapid target perception. Cognition and Emotion, 21, 964-981.

Murphy, S. T., Monahan, J. L., \& Zajonc, R. B. (1995). Additivity of nonconscious affect: Combined effects of priming and exposure. Journal of Personality and Social Psychology, 69, 589-602.

Murphy, S. T., \& Zajonc, R. B. (1993). Affect, cognition, and awareness: Affective priming with optimal and suboptimal stimulus exposures. Journal of Personality and Social Psychology, 64, 723-739.

Noulhiane, M., Mella, N., Samson, S., Ragot, R., \& Pouthas, V. (2007). How emotional auditory stimuli modulate time perception.
Emotion, 7, 697-704.

Öhman, A., Flykt, A., \& Esteves, F. (2001). Emotion drives attention: Detecting the snake in the grass. Journal of Experimental Psychology: General, 130, 466-478.

Öhman, A., \& Soares, J. J. F. (1994). "Unconscious anxiety': Phobic responses to masked stimuli. Journal of Abnormal Psychology, 103, 231-240.

Pelli, D. G. (1997). The VideoToolbox software for visual psychophysics: Transforming numbers into movies. Spatial Vision, 10, 437-442.

Phelps, E. A. (2006). Emotion and cognition: Insights from studies of the human amygdala. Annual Review of Psychology, 57, 27-53.

Phelps, E. A., Ling, S., \& Carrasco, M. (2006). Emotion facilitates perception and potentiates the perceptual benefits of attention. Psychological Science, 17, 292-299.

Rotteveel, M., de Groot, P., Geutskens, A., \& Phaf, R. H. (2001). Stronger suboptimal than optimal affective priming? Emotion, 1, 348-364.

Rubin, D. C., \& Friendly, M. (1986). Predicting which words get recalled: Measures of free recall, availability, goodness, emotionality, and pronunciability for 925 nouns. Memory and Cognition, 14, 79-94.

Ryan, T. A. (1960). Significance tests for multiple comparison of proportions, variances, and other statistics. Psychological Bulletin, 57, 318-328.

Sato, W., \& Aoki, S. (2006). Right hemispheric dominance in processing of unconscious negative emotion. Brain and Cognition, 62, 261-266.

Smith, S. D., Most, S. B., Newsome, L. A., \& Zald, D. H. (2006). An emotion-induced attentional blink elicited by aversively conditioned stimuli. Emotion, 6, 523-527.

Sweeny, T. D., Grabowecky, M., Paller, K., \& Suzuki, S. (2009). Within-hemifield perceptual averaging of facial expressions predicted by neural averaging. Journal of Vision, 9(3), 1-11. doi:10.1167/9.3.2. $<\mathrm{http}$ ://journalofvision.org/9/3/2/>.

Sweeny, T. D., Grabowecky, M., Suzuki, S., \& Paller, K. A. (2009). Long-lasting effects of subliminal affective priming from facial expressions. Consciousness and Cognition, 18, 929-938.

Tipple, J. (2010). Time flies when we read taboo words. Psychonomic Bulletin and Review, 17, 563-568.

Treisman, M. (1963). Temporal discrimination and the indifference interval: Implications for 
a model of the "internal clock". Psychological Monographs, 77, 1-31.

Tsuchiya, N., \& Adolphs, R. (2007). Emotion and consciousness. Trends in Cognitive Sciences, 11, 158-167.

Tsuchiya, N., \& Koch, C. (2005). Continuous flash suppression reduces negative afterimages. Nature Neuroscience, 8, 1096-1101.

Wittmann, M. (2009). The inner experience of time. Philosophical transactions of the Royal Society of London Series B - Biological Sciences, 364, 1955-1967.

Yang, E., Zald, D. H., \& Blake, R. (2007). Fearful expressions gain preferential access to awareness during continuous flash suppression. Emotion, 7, 882-886.
Table A1

List of the pictures (IAPS number).

\begin{tabular}{lll}
\hline Positive & Negative & Neutral \\
\hline 1710 & 2683 & 1303 \\
4220 & 6200 & 1726 \\
5833 & 6570.1 & 5920 \\
5910 & 6830 & 5940 \\
7502 & 8485 & 6900 \\
8190 & 9424 & 6910 \\
8370 & 9620 & 7640 \\
8470 & 9622 & 8160 \\
8499 & 9630 & 8192 \\
8501 & 9902 & 8475
\end{tabular}

